Culture et histoire dans l'espace roman

\title{
La escritura del cuerpo en Antes que anochezca de Reinaldo Arenas
}

\section{Armando Valdés-Zamora}

\section{(2) OpenEdition}

\section{Journals}

Edición electrónica

URL: https://journals.openedition.org/cher/8517

DOI: $10.4000 /$ cher.8517

ISSN: 2803-5992

\section{Editor}

Presses universitaires de Strasbourg

\section{Edición impresa}

Fecha de publicación: 30 junio 2010

Paginación: 51-60

ISBN: 978-2-35410-007-0

ISSN: 1968-035X

\section{Referencia electrónica}

Armando Valdés-Zamora, «La escritura del cuerpo en Antes que anochezca de Reinaldo Arenas», reCHERches [En línea], 4 | 2010, Publicado el 15 diciembre 2021, consultado el 26 enero 2022. URL: http://journals.openedition.org/cher/8517 ; DOI: https://doi.org/10.4000/cher.8517

\section{(c) (i) (5)}

Ce(tte) œuvre est mise à disposition selon les termes de la Licence Creative Commons Attribution -

Pas d'Utilisation Commerciale - Partage dans les Mêmes Conditions 4.0 International. 


\title{
La escritura del cuerpo en Antes que anochezca de Reinaldo Arenas
}

\author{
Armando Valdés-Zamora \\ Université de Paris XII
}

\section{Una historia imaginaria del cuerpo}

Cuatro discursos predominan en la definición de la identidad cubana. El de la excepción insular, el antillano y caribeño, del cual la isla, se dice, es el máximo representante, el discurso nacionalista, que es el predominante, y un cuarto, todavía no canonizado por la crítica que se configura en la segunda mitad de siglo XX: el de un sujeto marginal, errante o exilado que desde la experiencia de la lejanía o el aislamiento lee su espacio natural y confirma, universaliza o elude, los índices de la cubanidad.

En medio de esta insistencia por la diferencia de lo geográfico, que deja poco espacio para propuestas discursivas que sobrepasen la alteridad del Aquí-isla con el Allá-Otro, o viceversa, cabe preguntarse: ¿qué lugar podría ocupar un discurso sobre el cuerpo en esta gimnástica letrada? ¿De qué manera la escritura del cuerpo se ubica en la historia de una imaginación literaria que se reivindica cubana?

Es evidente que al referirme a la noción de historia imaginaria y a la de cuerpo, subyace una intención de invertir o cuestionar los puntos de vista tradicionales a partir de los cuales se ha querido clasificar la representación de lo cubano.

Una historia que sea imaginaria privilegia la subjetividad del escritor y el significado de las formas que inscriben la principal experiencia de éste, es decir, su escritura. Una historia de la imaginación debe entenderse como la 
historia de una doble realidad; estructural, es decir, de constantes formales, y otra espiritual, una historia de esa conciencia estructurante fundamento de toda estructura ${ }^{1}$. A grandes rasgos esto quiere decir que una doble realidad fundamenta el análisis: la espiritualidad del autor y la intención de delimitar la relación que existe entre la obra y la experiencia de la escritura; la manera en la que el escritor se dice el mismo. Más que una historia de formas se trata aquí de una historia de la imaginación de esas formas en escrituras que, de alguna u otra manera, son clasificadas como "cubanas".

Yo parto de la tesis de que en la escritura cubana la construcción de la imaginación como oposición a la realidad configura "un espacio interior" que trata con afirmaciones o negaciones, de legitimar una identidad. A la paradoja de estar (a)isla(dos) y de escribir con una lengua impuesta por el Otro, se contrapone la fundación de un nuevo territorio escrito en el cual predomina la imagen y la ficción de una forma: la de un cuerpo cuyas figuras terminan siendo la reproducción del propio cuerpo del sujeto. Más que una idealización mítica de lo insular y la elaboración de una inmanencia espiritual, es el itinerario de una encarnación lo que decide la construcción del sujeto escrito cubano.

Describir y situar en una historia de la imaginación literaria la manera en que se escribe el cuerpo en la autobiografía Antes que anochezca de Reinaldo Arenas, así como demostrar que este texto inaugura un nuevo canon vigente en las más recientes escrituras cubanas, son los objetivos de este trabajo.

\section{Modelos del cuerpo cubano}

Al menos tres modelos canónicos del cuerpo se pueden precisar en la imaginación literaria cubana antes del paradigmático año de 1959: el cuerpo histórico de Alejo Carpentier, el cuerpo metafórico de José Lezama Lima y el cuerpo frío de Virgilio Piñera (Valdés-Zamora 2004: 103-110).

En el caso de Carpentier, las tres formas que adopta su cuerpo escrito - el negro maravilloso, el sujeto blanco y el del personaje histórico - cumplen una función de mediador entre la Naturaleza y la Historia, son miembros de un paisaje y llevan en sí las cifras de una visión etnológica que prefiere ser

1 Se trata de una noción de Jean Starobinski citada por Jean Rousset (1968: 98). Estos tres teóricos son los principales representantes de la llamada «Escuela de la conciencia» o «Escuela de Ginebra». La noción de «historia de la imaginación» y la perspectiva crítica que ella propone y que desarrolla esta corriente crítica, están entre las bases teóricas principales del presente trabajo. Todas las traducciones del francés que aparecen aquí son mías. 
emblema de un continente más que de la isla. Son cuerpos configurados por la Historia y llevan consigo los estigmas de la confrontación del Aquí con el Allá.

El cuerpo lezamiano es de una mayor complejidad. Lezama identifica al texto con un cuerpo. El sujeto lezamiano encarna en un primer momento de su estética los emblemas insulares y más tarde los del barroco latinoamericano, para terminar siendo un modelo que reproduce el propio cuerpo del escritor. Sin embargo lo que lo distingue, más allá de sus valores representativos, es su libertad de asociación y la abertura semántica de sus figuras. La visión corporal de Lezama integra culturas, espacios y épocas diversas a una racionalidad contradictoria típica del exceso de su escritura barroca. La corporeidad de la escritura final de Lezama que insiste en la resistencia, el aislamiento, y la huida del cuerpo en el interior de la isla en la cual el Poder se apropia del exterior de la casa y del cuerpo, constituye una referencia clásica en la escritura cubana más reciente, y hasta cierto punto un antecedente de las memorias de Reinaldo Arenas.

Por su parte los fríos cuerpos piñerianos no están expuestos al tiempo de la Historia que envejece ni constituyen paradigmas de un unitario sistema de pensamiento. Son productos de un nihilismo descarnado, práctico y risueño que los hace aparecer fragmentados y sin otras sugerencias metafóricas que no sean las de su comportamiento absurdo en un espacio y un tiempo imprecisos.

Es este último cuerpo el más cercano al cuerpo sexualizado, homopoético, excesivo y negador que Reinaldo Arenas configura en su autobiografía.

\section{Un nuevo cuerpo entra al canon}

La paradoja entre el estatuto de escritura íntima que caracteriza a la autobiografía y el discurso excesivo y extrovertido a través del cual se representa el cuerpo del Sujeto, es en el plano expresivo, el primer signo distintivo de Antes que anochezca.

Es decir que se trata de un relato retrospectivo en prosa escrito en primera persona por alguien que cuenta su vida individual (Le Jeune 1996: 14). En el plano formal pudiera aludirse a una paradoja entre una escritura que se pretende personal y las alusiones al contexto histórico que podrían hacer creer que se trata más bien de unas memorias.

También es paradójico el discurso satírico a través del cual Arenas representa los cuerpos homosexuales de sus enemigos ideológicos o de sus 
amigos, si se tiene en cuenta que en la manera de narrar las vivencias de su metacuerpo (Dagognet 1992) él reivindica el erotismo homosexual.

Se puede además afirmar que existe una lógica hiperbólica tanto en la intencionalidad de Arenas como en su discurso, estructurándose así su imaginación en el movimiento de configuración y desfiguración de la forma del cuerpo. Por una parte se insiste en la transgresión protestataria que representan las acciones del cuerpo, se validan las mismas al insistir el narrador en ser testigo presencial de dicha transgresión, y por otra parte, se altera la memoria y el recuerdo porque la imaginación los desplaza por el exceso, forma y contenido de la imaginación en Antes que anochezca. Un exceso de las experiencias corporales, una deformación irracional del cuerpo que se escribe.

Las experiencias excesivas de los cuerpos del libro ponen en duda el criterio de veracidad que exige el género autobiográfico. Visto de esta manera, Antes que anochezca puede hasta cierto punto considerarse más una novela que el relato de un testimonio propio. ${ }^{2}$

A pesar de todas estas violaciones de las normas, en la breve introducción a Antes que anochezca Arenas respeta las reglas del pacto autobiográfico - las coincidencias de autor, narrador y personaje central - y enuncia también la adopción de los dos movimientos complementarios de toda autobiografía: la introspección y la retrospección.

La voluntad de exponer un testimonio íntimo en primera persona es entonces la primera función de esta escritura, antecedente en su tema y en su discurso de buena parte de la más reciente literatura cubana. ${ }^{3}$ Las otras dos funciones, sin duda referencias también de las ficciones que a partir de la década de los 90 aparecieron publicadas por autores cubanos, son la manera de representar su forma predominante, es decir el cuerpo del sujeto que narra su vida, y las políticas de esos cuerpos; sus relaciones de indiferencia, fuga o crítica (Détrez 2002) con respecto a la Historia, a la política y al Poder. Es decir, los intercambios de confrontación, evasión o condena de las experiencias corporales del Sujeto y sus relaciones intersubjetivas

2 "On arrive au paradoxe que, parfois, La couleur de l'été, qui se donne comme un roman, est plus proche de la réalité que Avant la nuit, une Autobiographie à considérer comme un roman de plus dans son œuvre», (HASSON 2007: 89).

3 En lo referente al tema homosexual se pueden mencionar al menos tres antecedentes de Antes que anochezca en la literatura cubana. Se trata de Alfonso Hernandez Catá, El angel de Sodoma 1929, Carlos Montenegro, Hombres sin mujer, 1937 y Calvert Casey, «Gianni», capítulo de la novela inconclusa Piazza Morgana. 
(Barthes 1982 cité par Huisman et Ribes 1992: 311) con el Cuerpo Político del régimen totalitario.

\section{Autoescritura del cuerpo canónico}

La experiencia del cuerpo que Arenas cuenta en Antes que anochezca, transcurre por la trilogía temporal de Eros-Chronos y Thánatos: nacimiento, vida y muerte.

Había comenzado como se verá más adelante mi autobiografía en Cuba. La había titulado Antes que anochezca, pues la tenía que escribir antes de que llegara la noche ya que vivía prófugo en un bosque. Ahora la noche avanzaba de nuevo en forma más inminente. Era la noche de la muerte. Ahora sí tenía que terminar mi autobiografía antes de que anocheciera. Lo tomé como un reto. Y seguí así trabajando en mis memorias. (Arenas 1992:11)

El libro comienza por el final de su cuerpo, es la autobiografía donde se anuncia la muerte inminente del sujeto. De esta manera lo narrado puede considerarse a su vez como un testamento. La decisión editorial de poner la carta de despedida de Arenas a manera de epílogo para cerrar el libro, persigue este objetivo.

A pesar de esto Antes que anochezca narra de manera cronológica y por temas, el ciclo vital de Arenas: su niñez, su juventud, su formación literaria autodidacta en La Habana y su exilio en los Estados Unidos.

Desde el principio hay una interrelación entre el acto de escribir y el cuerpo, entre los efectos ambivalentes de los dos gestos: el esfuerzo y el placer. Para él escribir, "era como la culminación o el complemento de todos los demás placeres y también de todas las demás calamidades» (135).

$\mathrm{Al}$ intentar sobrevivir evitando las modelaciones formales del Poder, el cuerpo de Arenas padece la soledad precaria y la represión que lo lleva, precisamente, a la fuga y al refugio en el Parque Lenin hasta su arresto y posterior encarcelamiento durante varios meses. Es decir las calamidades provienen de la reducción de su libertad individual por la aplicación de la ley. El texto se genera entonces como prueba y protesta desde este refugio temporal.

Es a través de la sexualidad que el cuerpo marca la presencia del narrador testigo, sus edades y su sociabilidad. El erotismo constituye - junto a la escritura - la práctica a través de la cual se manifiestan los placeres del cuerpo y del texto. En la descripción de los años de su infancia, el narrador afirma lo siguiente: 
Creo que siempre tuve una gran voracidad sexual. No solamente las yeguas, las puercas, las gallinas o las guanajas, sino también todos los animales fueron objeto de mi pasión sexual, incluyendo a los perros. [...]

Aquella etapa entre los siete y los diez años fue para mí de gran erotismo, de una ferocidad sexual que, como ya dije, casi lo abarcaba todo. Abarcaba la naturaleza en general, pues también abarcaba a los árboles (39).

Como veremos más adelante, a esta relación natural del cuerpo con el espacio, que podría inducir a relacionar la poética corporal de Arenas con los barrocos de Carpentier y Lezama, le sigue la transgresión de las normas y los signos de una biopolítica impuestos por el Poder. Es a través de esta capacidad de concebir el cuerpo propio como superficie de una escritura que se niega a obedecer el texto de la ley y que transforma al cuerpo entonces evocado al final de su vida, en memoria, que se inaugura una nueva extrañeza en el canon literario cubano, un nuevo cuerpo. Un cuerpo a la vez politizado y erótico, expresión de un deseo de libertad y por tanto objeto de una ruptura que a su vez lo daña y lo libera.

Se puede inferir que Arenas se reconoce a través de las acciones que afirman por un lado su libertad extrema de poder decir y hacer, de escribir y contarse - lo que Paul Ricœur en su Parcours de la reconnaissance nombra «Una fenomenología del hombre capaz» - y por otra las acciones que niegan y se oponen a una economía política del cuerpo ordenada por el Poder, por el conjunto de elementos materiales y de técnicas que permiten a este Poder hacer del cuerpo del individuo un objeto de sometimiento y de obediencia (Foucault 1975).

Establecer una racionalidad del deseo del cuerpo de Arenas, de su discurso y de su práctica nos obliga a referirnos a una lógica del exceso, a una escritura hiperbólica que quiere "decir todo" a través del testimonio pero también de la imaginación. Al describir los cuatro tipos de homosexuales que según él existían en la época, Arenas aprovecha para vengarse de muchas personas del mundo cultural habanero que él conocía. Al explicar qué caracteriza al primer grupo de estos intelectuales él escribe:

La loca tapada era aquella que, siendo loca, casi nadie lo sabía. Se casaban, tenían hijos, y después iban a los baños, clandestinamente, llevando al dedo índice el anillo matrimonial que le hubiese regalado su esposa. Era difícil a veces reconocer a la loca tapada; muchas veces condenaban ellas mismas a los homosexuales. Los ejemplos de este tipo de loca son miles, pero uno de los más típicos es el caso del dramaturgo Nicolás Díaz, quien, una vez, en un acto de desesperación, terminó introduciéndose un bombillo en el ano. Y aquel hombre, que era militante de la Juventud Comunista, no tuvo 
forma de explicar cómo aquel bombillo había ido a parar a aquella parte del cuerpo. Fue expulsado de esa organización con gran escándalo. (Arenas 1992: 104-105)

En este caso la paradoja de ridiculizar un cuerpo homosexual como el suyo, puede comprenderse si se tiene en cuenta que dicho cuerpo lleva en sí de manera hipócrita los signos de la heterosexualidad - el anillo - y las marcas del Cuerpo Político : «era militante de la Juventud Comunista».

El erotismo contamina la retórica hasta el punto que la mancha ${ }^{4}$ a la que se refiere Georges Bataille «que puede llegar a la abyección (Kristeva) cuando se trata del cuerpo del Otro que encarna la ideología de la ley», adquiere también connotaciones políticas:

Algunos profesores, por no decir la mayoría, tenían sus relaciones sexuales con los alumnos; había uno, llamado Juan, que había tenido relaciones con un centenar de estudiantes. A veces, frente a su cuarto, los jóvenes hacían colas para templárselo; todo eso yo lo vi. Además uno de mis compañeros, famoso por tener uno de los falos más grandes de toda la escuela, me contaba que era uno de los favoritos de aquel profesor de marxismo. (Arenas 1992: 74)

Se puede así hablar de una alteridad deseada (Buci-Gluksmann 1984: 184), hay una proliferación del significante más allá de la significación simple o afirmativa de una imagen homosexual del cuerpo masculino. Este puede ser deseado o repulsivo, asumido o rechazado. La principal causa de esta ambivalencia del cuerpo es la contradicción que en Arenas es irreconciliable entre el cuerpo libre y el sometido. El cuerpo que quiere escapar a las estrategias colectivas del Poder para doblegarlo y el que las acepta y con dicha aceptación representa la poética corporal del estado totalitario.

En su manifiesto "Grito, luego existo » de su libro de ensayos Necesidad de libertad (Arenas 1991), Arenas identifica su voluntad de rebeldía con la posibilidad de elegir sus actos corporales. Es la expresión del cuerpo, más que el derecho téorico a la acción o a la expresión, quien se prioriza como emblema de la libertad:

Grito, luego existo. Pues sí, por encima de todo, alguna condición que define al ser humano es su necesidad de libertad, la falta de ella conlleva todas las calamidades, no sólo las intelectuales o espirituales, sino también el simple hecho de comer, fornicar o respirar. Pues un sistema totalitario, una tiranía, una dictadura, precisamente por ser una acción infamante, contamina, corrompe y reduce a todos los que bajo ella viven y de alguna manera socava y disminuye a todo el género humano (22-23).

4 La mancha es una propuesta de traducción para la noción de la souillure de Bataille. 
Es a través de las tensiones que se producen entre la actividad del cuerpo del Sujeto y la ley, en las respuestas de dicho Sujeto ante la coacción del poder, y sobre todo, en la transgresión de las normas y los límites impuestos por el Estado, donde se registran los índices canónicos de esta escritura autobiográfica del cuerpo.

Arenas detalla de la siguiente manera una supuesta erotización colectiva en La Habana de los sesenta en momentos en que se acentúa la represión contra los llamados antisociales:

De todos modos, la juventud de los años sesenta se las arregló, no para conspirar contra el régimen, pero sí para hacerlo a favor de la vida. Clandestinamente seguíamos reuniéndonos en las playas o en las casas o, sencillamente, disfrutábamos de una noche de amor con algún recluta pasajero, con una becada o algún adoslescente desesperado que buscaba la forma de escapar a la represión. Hubo un momento en que se desarrolló, de forma oculta, una gran libertad sexual en el país; todo el mundo quería fornicar desesperadamente y los jóvenes se dejaban melenas que, por supuesto, eran perseguidas por mujeres menopáusicas provistas de largas tijeras, se vestían con ropa estrecha y se ponían sellos al estilo occidental; oían a los Beatles y hablaban de liberación sexual. Enormes cantidades de jóvenes nos reuníamos en Coppelia, en la cafetería del Capri o en el Malecón, y disfrutábamos de la noche a despecho del ruido de las perseguidoras de la policía. (Arenas 1992: 116-117)

Erotismo y escritura son las vías de expresión utilizadas contra la política corporal promovida por el estado expresadas en este caso a través de una superposición de experiencias disímiles. La memoria corporal se construye más sobre la tensión de un lenguaje que exagera y encadena sus imágenes que sobre la fidelidad de los recuerdos. Si el objetivo es doble, resaltar las proezas del cuerpo homosexual y ridiculizar al del Otro enemigo, vía personal de desacralizar al Poder, en ambos casos la imaginación sobrepasa la lógica de la remembranza. Cuando Arenas dice haber calculado en unos cinco mil el número de sus amantes en aquella época, la exageración provoca más hilaridad que un sentimiento de libertad.

Como hemos visto hay siempre una intención de oposición en Arenas al escribir su cuerpo, eje de la narración y de la actividad de los otros como testigo y por tanto, prueba de la veracidad de lo que dice.

Esta oposición se origina también por la aceptación del desvío simbólico que significa ser homosexual. Su exceso se intensifica por el deseo de añadir, de extender, de ganar por la suma de gestos más que por la palabra misma. 
Es también de esta manera que el cuerpo de Arenas escapa a la ley, a la lengua única que desea uniformizar las múltiples lenguas del cuerpo del individuo. Bajo la vigilancia de la ley que prohibe y estigmatiza, el cuerpo es el espacio del delito, el lugar de la ambivalencia. Su cuerpo resiste a la inscripción del nombre designado por el poder, llámese disidente, antisocial, traidor u homosexual. O lo que es lo mismo, resiste a la significación única que excluye lo diverso y lo posible.

Vale preguntarse ¿qué hace canónico a este cuerpo? ¿Qué lo convierte en una referencia, por su extrañeza al hablar de la literatura cubana contemporánea?

El cuerpo de Arenas en Antes que anochezca no es el significante de un corpus ideológico que trate de especular sobre los valores de una identidad cultural, como es el caso del cuerpo escrito de Alejo Carpentier.

Más cerca del cuerpo final de Lezama en su poemario póstumo Fragmentos a su imán que del barroco latinoamericano encarnado por el sujeto metafórico ideal de La expresión americana y Las eras imaginarias, es decir, José Martí, Arenas no necesita un modelo como referencia o teleología: él es su propio modelo. Tampoco busca la afirmación de una identidad representativa de la isla o del continente. El exceso de la política de su cuerpo y de sus experiencias va dirigido a la anulación del Sujeto, es decir, hacia la muerte.

Es precisamente esta negación, la ausencia de asimilación sugerente de la naturaleza y de sus símbolos, la carencia de una espiritualidad, y ese exceso que ridiculiza a veces por ser grotesco o expresionista, lo que lo afilia a la estética de Virgilio Piñera, a sus cuerpos fríos.

La expresión corporal preferida del cuerpo de Antes que anochezca es el grito. Si bien esta negación rotunda y el hecho de autoescribirse pueden considerarse como una limitación semántica de la representación del cuerpo, debe reconocerse que en la expansión de este cuerpo como carne (Merleau-Ponty), es decir como omnipresencia en el mundo y en la transgresión de todos los límites, se recupera y salva al cuerpo escrito cubano de los códigos del totalitarismo, al sujeto que con su metacuerpo reemplaza también al formalismo de su conciencia por la comunicación sensorial y marca, con nuevos signos, la memoria de esta literatura. 


\section{Bibliografía}

Arenas, Reinaldo, 1991, Necesidad de libertad, Miami, Ediciones Universal.

Arenas, Reinaldo, 1992, Antes que anochezca, Barcelona, Tusquets Editores.

Barthes, Roland, 1982, «Encore le corps», Critique, août-septembre.

Bataille, Georges, 1957, L'érotisme, Paris, Éditions de Minuit.

Buci-Gluksmann, Christine, 1984, La raison baroque de Baudelaire à Benjamin, Paris, Éditions Galilée.

Dagognet, François, 1992, Le corps multiple et un, Paris, Les empêcheurs de penser en rond.

Détrez, Christine, 2002, La construction sociale du corps, Paris, Seuil.

Foucault, Michel, 1975, Surveiller et punir, Paris, Gallimard.

Hasson, Liliane, 2007, Un Cubain libre, Reinaldo Arenas, photographies de Suzanne NAGY, Paris, Actes Sud.

Huisman, Bruno et Ribes, François, 1992, Les philosophes et le corps, Paris, Dunod.

Kristeva, Julia, 1980, Pouvoir de l'horreur, essai sur l'abjection, Paris, Seuil.

Le Jeune, Philippe, 1996, Le Pacte autobiographique, Paris, Seuil.

Merleau-Ponty, Maurice, 1964, Le visible et l'invisible, Paris, Gallimard.

Ricœur, Paul, 2004, Parcours de la reconnaissance, Paris, Editions Stock.

Rousset, Jean, 1968, "Les réalités formelles de l'œuvre» in Les chemins formels de la critique, George Poulet (éd), Paris, 10/18.

Valdés-Zamora, Armando, 2004, «El cuerpo como memoria literaria cubana: Carpentier, Lezama y Piñera», América (31) Actes du $8^{\mathrm{e}}$ Colloque International du CRICCAL «Mémoire et formes culturelles», T-II, Paris, Presses de la Sorbonne Nouvelle, p. 103-110. 